Research Article

\title{
Study of Awareness about Blood Donation among Blood Donors in a Tertiary Care Hospital
}

\author{
Mourouguessine Vimal', Bhuvana $]^{2}$, Anandabaskar Nishanthi ${ }^{3}$
}

${ }^{1}$ Associate Professor, ${ }^{2}$ Undergraduate Student, Department of Pathology, Sri Manakula Vinayagar Medical College and Hospital, Puducherry, India.

${ }^{3}$ Assistant Professor, Department of Pharmacology, Sri Manakula Vinayagar Medical College and Hospital, Puducherry, India. DOI: https://doi.org/10.24321/2454.8642.201921

\section{I $\quad \mathbf{N} \quad \mathbf{F} \quad \mathbf{O}$}

\section{Corresponding Author:}

Mourouguessine Vimal, Department of Pathology, Sri Manakula Vinayagar Medical College and Hospital, Puducherry, India.

E-mail Id:

drvimalm@gmail.com

Orcid Id:

https://orcid.org/0000-0003-1761-575X

How to cite this article:

Vimal M, Bhuvana J, Nishanthi A. Study of Awareness about Blood Donation among Blood Donors in a Tertiary Care Hospital. Rec Adv Path Lab Med 2019; 5(4): 13-16.

Date of Submission: 2019-11-20

Date of Acceptance: 2019-12-03

\section{$\begin{array}{llllllll}\mathbf{A} & \mathbf{B} & \mathbf{S} & \mathbf{T} & \mathbf{R} & \mathbf{A} & \mathbf{C} & \mathbf{T}\end{array}$}

Background: Various factors determine the donor's frequency of blood donation like lack of awareness, life style barriers and their present and past experience with blood donation.

Aim and Objectives: To study the awareness about blood donation among the blood donors of a tertiary care hospital and to find out the existing information gap.

Materials and Methods: This was a cross sectional study conducted in the blood bank of a tertiary care hospital in which the blood donors, after obtaining informed consent, were administered a questionnaire to assess their awareness about blood donation. The collected data was entered in an excel sheet and it was analyzed.

Result: Out of the 100 blood donors included in the study, majority of them were in the age group 21-30 years. Most (94\%) of the donors were aware of their blood group and had the knowledge that they can continue their routine work after blood donation (92\%). However, only (52\%) were aware of the rejection criteria and only (59\%) had awareness about age criteria for blood donation and required weight and hemoglobin for blood donation. (67\%) of the donors had awareness about blood donation from the media and friends, while others gained it from their previous blood donation experience.

Conclusion: Training programs for health professionals and awareness programs in mass media can spread the knowledge of blood donation among the community especially in the younger generation and improve their attitude and sustain their practice of regular blood donor.

Keywords: Blood Donation Awareness, Blood Donors, Blood Bank, Rejection Criteria for Blood Donation, Voluntary Blood Donation

\section{Introduction}

The need for blood requirement is on high with the increase in life expectancy, chronic diseases and cancer, and technical advancement in the modern medical practice. ${ }^{1}$ India with a population of more than 1.3 billion requires 12 million blood units every year. On the contrary, only 6.8 million blood units could be supplied by the blood banks. In spite 
of conducting awareness programs and blood donation camps, most blood banks often struggle to meet the existing demand for blood products. ${ }^{2}$ Various factors determine the donor's frequency of blood donation like lack of awareness, life style barriers, and their present and past experience with blood donation. Absence of voluntary blood donation is a main challenge in many countries. Hence it is essential to find the awareness about blood donation among the blood donors to find out the existing information gap so that they can be counseled and clarified with their queries to become a regular future blood donor.

\section{Materials and Methods}

This was a cross sectional study carried out at the registered blood bank of Sri Manakula Vinayagar medical college and hospital, a tertiary care hospital in rural Puducherry, for a period of three months from July 2019 to September 2019. The study was initiated after getting clearance from the Institutional ethics committee.

\section{Inclusion Criteria}

Voluntary and replacement donors visiting the blood bank for blood donation during the study period were included.

\section{Exclusion Criteria}

Donors who had been deferred for blood donation and donors who were not willing to participate in the study were excluded.

A total of 100 blood donors, who had been screened for blood donation and after their donation of blood and adequate rest, were informed about the details of the study. A written informed consent was obtained from them and were administered a questionnaire. The questionnaire included the details of their demographic characteristics and questions which assessed their knowledge, attitude and practice of blood donations. The data were entered in excel sheet and frequency and distribution of each variable were calculated.

\section{Result}

Table I.Demographic characteristics of the blood donor

\begin{tabular}{|c|c|c|}
\hline \multicolumn{2}{|c|}{ Demographic characteristics } & Number \\
\hline \multirow{4}{*}{ Age } & $18-20$ & 11 \\
\cline { 2 - 3 } & $21-30$ & 67 \\
\cline { 2 - 3 } & $31-40$ & 19 \\
\cline { 2 - 3 } & $41-50$ & 3 \\
\hline \multirow{3}{*}{ Gender } & Male & 99 \\
\cline { 2 - 3 } & Female & 1 \\
\hline \multirow{2}{*}{$\begin{array}{c}\text { Marital } \\
\text { status }\end{array}$} & Married & 71 \\
\cline { 2 - 3 } & Unmarried & 29 \\
\hline
\end{tabular}

\begin{tabular}{|c|c|c|}
\hline \multirow{4}{*}{$\begin{array}{c}\text { Educational } \\
\text { status }\end{array}$} & Graduate & 57 \\
\cline { 2 - 3 } & Diploma & 7 \\
\cline { 2 - 3 } & High school & 29 \\
\hline \multirow{3}{*}{ Occupation } & Illiterate & 7 \\
\cline { 2 - 3 } & $\begin{array}{c}\text { Labourers/ Industrial } \\
\text { workers }\end{array}$ & 61 \\
\cline { 2 - 3 } & Professionals & 32 \\
\cline { 2 - 3 } & Student & 7 \\
\hline
\end{tabular}

Out of the 100 blood donors included in the study, majority of them were in the age group 21-30 years, followed by 19 donors in the age group 31-40 years. During the study period, only one female donor donated the blood and rest 99 were males. $71 \%$ of the donors were married and $57 \%$ of the donors were graduates. $64 \%$ of the donors were graduates and diploma holders, $29 \%$ completed their high school and 7\% were illiterate. Most of the donors were labourers and industrial workers (61\%), followed by professionals (32\%) and 7\% were students. The basic demographic profile of the donors was summarized in the Table 1.

Table 2.Donors awareness about the process of blood donation

\begin{tabular}{|c|c|}
\hline Awareness about blood donation & Number \\
\hline Donors blood group & 94 \\
\hline Volume of blood collected from the donor & 73 \\
\hline Screening tests done on the collected blood & 81 \\
\hline $\begin{array}{c}\text { Donor can continue routine work after } \\
\text { blood donation }\end{array}$ & 92 \\
\hline $\begin{array}{c}\text { Rejection criteria for blood donation } \\
\text { subsequent blood donations }\end{array}$ & 52 \\
\hline $\begin{array}{c}\text { Minimum and maximum age for blood } \\
\text { donation }\end{array}$ & 59 \\
\hline $\begin{array}{c}\text { Minimum weight and hemoglobin required } \\
\text { for blood donation }\end{array}$ & 59 \\
\hline
\end{tabular}

Most (94\%) of the donors were aware of their blood group and had the knowledge that they can continue their routine work after blood donation (92\%). However, only $52 \%$ were aware of the rejection criteria and only $59 \%$ had awareness about age criteria for blood donation and required weight and hemoglobin for blood donation (Table 2). $67 \%$ of the donors had awareness about blood donation from the media, friends and relatives while others had from their previous blood donation experiences.

\section{Discussion}

In spite of extensive research, a true substitute for blood 
and blood products is not available yet. ${ }^{3}$ The ever-increasing need for blood transfusion can be met only by promoting the practice of voluntary blood donation. Voluntary blood donation also minimizes the risk of transfusion transmissible infections. ${ }^{4}$ Achieving $100 \%$ voluntary blood donors is a big challenge for every blood bank, but this can be easily achieved, if $1 \%$ of a nation practice voluntary blood donation. ${ }^{5}$ However misconceptions, poor knowledge about blood donation practices can impact the attitude of the blood donor. ${ }^{6}$ Hence there is a need to assess and improve the knowledge of the blood donors.

In our study $78 \%$ of the donors were of the age group 18-30 years and they had some awareness about blood donation. However, the existing misconceptions and myths about blood donation should be clarified to the community including to the younger generation donors. Educational programs highlighting the importance of blood donation can be incorporated as part of curriculum which will encourage them to practice lifelong voluntary blood donation.

Though the donors were aware of their blood group (94\%) and a knowledge that they can continue their routine work after blood donation (92\%), only 52\% were aware of most of the rejection criteria and $59 \%$ only had awareness about age criteria for blood donation and required weight and hemoglobin for blood donation. Hence there is a need to educate the community about the blood donor selection criteria and create awareness which will self-motivate the donors and increase the acceptance rate of blood donors. ${ }^{7}$

In our study, $64 \%$ of the donors were were graduates and diploma holders and this could have contributed to the increased awareness about blood donation in them. Hence educational status of the donors plays a significant role in improving their knowledge and positive attitude towards blood donation. ${ }^{8-10} \mathrm{~A}$ study conducted by Elnajeh $\mathrm{M}$ et al. found that. ${ }^{11}$ found that majority of the participants who had good knowledge and attitude regarding blood donation, but had a poor practice.

Studies ${ }^{11,12}$ have shown that females have good knowledge about blood donation when compared to males. However, in our study, gender comparison was not possible as we had only one female donor during the study period. The reason for less proportion of female donors in the developing nations is because of the increased prevalence of anemia in the females. Hence there arises a need to improve the nutritional status of the females to practice the blood donation.

This study was exclusively conducted in the blood donors. Some of the donors were even regularly donating blood. Thus, they might have gained the awareness about blood donation from their previous experiences. Hence, similar studies should be conducted at the community level to assess their awareness about blood donation, which could aid in planning future blood donation awareness programs and increase the practice of voluntary blood donation.

\section{Conclusion}

Though most of the donors in the study were aware of the blood donation procedures, still some have misconceptions and were not aware of the rejection criteria and volume of the blood collected and the screening tests done on the blood collected. Training programs for health professionals and awareness programs in mass media can spread the knowledge of blood donation among the community especially in the younger generation and improve their attitude and sustain their practice of regular blood donor.

\section{Conflict of Interest: None}

\section{References}

1. Gebresilase HW, Fite RO, Abeya SG. Knowledge, attitude and practice of students towards blood donation in Arsi university and Adama science and technology university: a comparative cross-sectional study. BMC Hematol 2017; 17(20): 1-10. Available from: https:// bmchematol.biomedcentral.com/articles/10.1186/ s12878-017-0092-x [PubMed/ Google Scholar].

2. Tadesse W, Ayalew Y, Yisma E, Liben ML, Wudu M. Knowledge, attitude, practice and associated factors towards voluntary blood donation among regular health science students of Samara University, Ethiopia. Health Sci J 2018; 12(1): 542. Available from: http:// www.hsj.gr/medicine/knowledge-attitude-practiceand-associated-factors-towards-voluntary-blooddonation-among-regular-health-science-students-ofsamar.php?aid=21795 [Google Scholar].

3. Lowe KC, Ferguson E. Benefit and risk perceptions in transfusion medicine: blood and blood substitutes. $J$ Intern Med 2003; 253(5): 498-507. Available from: https://onlinelibrary.wiley.com/doi/full/10.1046/ j.1365-2796.2003.01149.x?sid=nlm\%3Apubmed [PubMed/ Google Scholar].

4. Bachhotiya A, Arora VK, Mahashabde P. Evaluation of Intervention on Voluntary Blood Donation among 1st Prof Medical and Dental Students of Index Medical College, Indore (MP), India. Natl J Community Med 2014; 5(2): 223-226. Available from: http://njcmindia. org/uploads/5-2_223-226.pdf [Google Scholar].

5. Ponmari JS, Sivaraman M, Balasubramanian A. A study on knowledge, attitude and practice on blood donation among medical students in a tertiary care teaching hospital, Chennai, Tamil Nadu, India. Int J Basic Clin Pharmacol 2016; 5(3): 802-804. Available from: https://www.ijbcp.com/index.php/ijbcp/article/ view/345 [Google Scholar].

6. Abolfotouh MA, Al-Assiri MH, Al-Omani M et al. Public 
awareness of blood donation in Central Saudi Arabia. Int J Gen Med 2014; 7: 401-410. Available from: https:// www.ncbi.nlm.nih.gov/pmc/articles/PMC4140232/ [PubMed/ Google Scholar].

7. Vimal M, Sowmya S, Nishanthi A et al. Evaluation of blood donor deferral causes: a retrospective study from South India. Ann Pathol Lab Med 2016; 3(6): A605611. Available from: https://www.pacificejournals. com/journal/index.php/apalm/article/view/apalm1006 [Google Scholar].

8. Mwaba K, Keikelame MJ. Blood donation behaviour and beliefs among a sample of high school students in Mmabatho. Curationis 1995; 18(3): 2-3. [PubMed/ Google Scholar].

9. Wiwanitkit V. Knowledge about blood donation among a sample of Thai university students. Vox Sang 2002; 83(2): 97-99. Available from: https://onlinelibrary.wiley. com/doi/abs/10.1046/j.1423-0410.2002.00209.x?sid =nlm\%3Apubmed [PubMed/ Google Scholar].

10. Hosain GM, Anisuzzaman M, Begum A. Knowledge and attitude towards voluntary blood donation among Dhaka University students in Bangladesh. East Afr Med J. 1997; 74(9): 549-553. Available from: https:// europepmc.org/article/med/9487428 [PubMed/ Google Scholar].

11. Elnajeh M, Ghazi HF, Abdalqader MA, Baobaid MF. Knowledge, attitude and practice towards blood donation and its associated factors among university students in Shah Alam, Malaysia. Int J Community Med Public Health 2017; 4(7): 2230-2233. Available from: https://pdfs.semanticscholar.org/efcc/ e88ab7cdd3167165c81e7d2920a46b693259.pdf [Google Scholar/ ResearchGate].

12. Nigatu A, Demissie DB. Knowledge, Attitude and practice on voluntary blood donation and associated factors among Ambo University regular students, Ambo Town, Ethiopia. J Community Med Health Educ 2014; 4(05): 315. Available from: https://www.omicsonline. org/open-access/knowledge-attitude-and-practiceon-voluntary-blood-donation-and-associated-factorsamong-ambo-university-regular-students-ambo-townethiopia-2161-0711-4-315.php?aid=35869 [Google Scholar/ ResearchGate]. 